hand SF as measured by BrdU proliferation assay $(p<0.05, n=3)$. Apoptosis of hand SF increased at 48 hour of HOTTIP silencing $(p<0.05, n=3)$.

Conclusions: The IncRNA HOTTIP, which is specifically expressed in hand joints via epigenetic mechanisms, is a master regulator of mitotic cell cycle genes and proliferation in hand SF. Distal-specific expression of HOTTIP might imprint hand SF with enhanced proliferative potential, thereby shaping the location-specific joint pathology, e.g. prominent synovial hyperplasia and increased severity of hand arthritis in RA.

Disclosure of Interest: M. Frank Bertoncelj Grant/research support from: euroTEAM, BTCure, IRR, Promedica, Georg und Berta Schwyzer Winiker Grant, T. Masterson: None declared, E. Karouzakis Grant/research support from: BTCure GSK, C. Kolling: None declared, A. Filer: None declared, C. Buckley: None declared, S. Gay Grant/research support from: euroTEAM, BTCure, GSK, IRR, O Distler Grant/research support from: Abbvie, Actelion, Bayer, Biogenldec, Boehringer Ingelheim, ChemomAb, espeRare foundation, Genentech/Roche, GSK, Inventiva, iQone, Lilly, medac, Medlmmune, Mepha, MSD, Mitsubishi Tanabe Pharma, Novartis, Pfizer, Pharmacyclics, Sanofi, Sinoxa and UCB, Consultan for: Abbvie, Actelion, Bayer, Biogenldec, Boehringer Ingelheim, ChemomAb, espeRare foundation, Genentech/Roche, GSK, Inventiva, iQone, Lilly, medac Medlmmune, Mepha, MSD, Mitsubishi Tanabe Pharma, Novartis, Pfizer, Pharmacyclics, Sanofi, Sinoxa and UCB, C. Ospelt Grant/research support from: euroTEAM, BTCure, CABMM, IRR, Promedica

DOI: 10.1136/annrheumdis-2018-eular.6757

\section{SAT0067 ROLE OF NOX2-DERIVED REACTIVE OXYGEN SPECIES IN S100A8/A9-DRIVEN INFLAMMATORY OSTEOARTHRITIS}

N. Kruisbergen, S. van Dalen, M. van den Bosch, A. Blom, P. van Lent.

Experimental Rheumatology, Radboudumc, Nijmegen, Netherlands

Background: Synovitis in inflammatory osteoarthritis $(O A)$ is driven by locally released DAMPs like S100A8/A9 proteins that have been shown to enhance joint destruction. S100A8/A9 induce ROS (reactive oxygen species) release by phagocytes in OA synovium via the NADPH-oxidase 2 (NOX2)-complex. Assembly of this complex is dependent on the neutrophils cytosolic factor (Ncf1). In this complex, the NOX2 protein is responsible for ROS production.

Objectives: In the present study we investigated whether NOX2-derived ROS are involved in joint pathology during collagenase-induced $\mathrm{OA}(\mathrm{CiOA})$.

Methods: CiOA was induced in knee joints of wild type (WT) and Ncf1-deficient $\left(\mathrm{Ncf1}^{* / *}\right)$ mice. Synovial gene expression of NOX2-subunits was measured with qRT-PCR. Joint pathology was assessed using histology and antibodies against aggrecan neo-epitope VDIPEN. Levels of inflammatory proteins were measured with Luminex or ELISA. Phagocytes present in synovium, blood, bone marrow and spleen were analysed with flow cytometry. Extracellular ROS production by bone marrow-derived phagocytes was measured using an Amplex Red ROS detection assay.

Results: CiOA induction in knee joints of WT mice caused significantly increased synovial gene expression of NOX2 subunits. On day 7 of $\mathrm{CiOA}$, synovial thickening, synovial S100A8/A9 levels and synovial percentages of inflammatory macrophages, PMNs, and monocytes were comparable between WT and $\mathrm{Ncf}^{1^{* / *}}$ mice. Cartilage damage and MMP activity, as measured by VDIPEN staining, were comparable, as well as levels of inflammatory mediators in serum and phagocyte percentages in blood, bone marrow and spleen. On day 42 of $\mathrm{CiOA}$, synovitis, cartilage damage, and osteophyte formation in $\mathrm{Ncf}^{* / *}$ mice were unaltered when compared to WT mice. ROS production by $\mathrm{Ncf1}^{* / *} \mathrm{PMNs}$ was completely absent but $\mathrm{Ncf1}^{* / *}$ macrophages, the more predominant phagocyte involved in development of pathology during CiOA, produced ROS in similar amounts as WT macrophages. Ncf1 deficiency thus seems to exclusively affect PMNs, this surprising finding might explain the lack of differences observed between CiOA development in WT and $\mathrm{Ncf1}^{\star / *}$ mice. ROS production by WT and $\mathrm{Ncf1}^{* / *}$ macrophages was strongly upregulated by S100A8 and almost completely inhibited by the pan-NOX inhibitor diphenyleneiodonium chloride (DPI). In order to determine whether NOX1 complexes caused the compensation responsible for Ncf1 independent ROS production, we co-stimulated $\mathrm{Ncf}^{* / *}$ macrophages with NOX1-specific inhibitor ML171. However, no ML171-induced inhibition of ROS production was observed.

Conclusions: Absence of PMN-derived ROS does not alter synovitis and joint pathology in S100A8/A9-driven experimental inflammatory OA. The mechanism that enables Ncf1-independent ROS production by macrophages should be further investigated.

Disclosure of Interest: None declared

DOI: 10.1136/annrheumdis-2018-eular.5421

\section{SAT0068 \\ BILIRUBIN PROMOTES DOWN-REGULATION OF RUNX2 AND UP-REGULATION OF RANKL GENE EXPRESSION IN BONE EXPLANTS AND IN OSTEOBLASTIC AND OSTEOCYTIC CELL LINES}

S. Ruiz-Gaspà, A. Parés, A. Combalia, P. Peris, A. Monegal, N. Guañabens. Metabolic Bone Diseases and Liver Units, Hospital Clínic, Idibaps, Ciberehd, University of Barcelona, Barcelona, Spain, Barcelona, Spain

Background: In vitro studies have shown that the retained substances of cholestasis have deleterious effects in human osteoblasts and osteocytic cells. Bilirubin (BIL) and lithocholic acid (LCA) induce alterations in the proliferation, differentiation and apoptosis of osteoblastic and osteocytic cells. However, their effects in human bone tissue and in bone cell lines have not been deeply analysed.

Objectives: To investigate the effects of BIL, LCA and ursodeoxycholic acid (UDCA) in gene expression of human trabecular bone explants as well as in osteoblastic (SAOS2) and osteocytic cells (MLO-Y4/MLO-A5).

Methods: Bone tissue harvested from trabecular bone fragments, SAOS2 and MLO-Y4/MLO-A5 cells were cultured and treated with BIL $(50 \mu \mathrm{M})$, LCA $(10 \mu \mathrm{M})$ and UDCA $(10 / 100 \mu \mathrm{M})$ for 24 hour. Gene expression of osteocalcin (BGLAP) Cbfa1 (RUNX2)/Osterix (OSX) and RANKL (TNFRSF11)/osteoprotegerin (TNFRSF11B) were quantified by real time PCR.

Results: BIL diminishes RUNX2 gene expression in bone tissue (-37\%), SAOS2 (-75\%), MLO-Y4 (-56\%) and MLO-A5 (-77\%), and increases RANKL expression in $60 \%, 27 \%, 72 \%$ and $60 \%$, respectively $(\mathrm{p} \leq 0.02)$. In bone tissue and in osteoblastic and osteocytic cells, LCA increases gene expression of BGLAP (NS) and RANKL (p $\leq 0.03)$. UDCA $100 \mu \mathrm{M}$ increases RUNX2 and OSX expression in bone tissue (78\% and $82 \%)$, MLO-Y4 (72\% and $80 \%)$ and SAOS2 $(75 \%$ and $70 \%)(\mathrm{p} \leq 0.03)$. In addition, UDCA $100 \mu \mathrm{M}$ significantly increases expression of BGLAP, OPG and RANKL in bone tissue and in osteocytic lines. UDCA 10/ $100 \mu \mathrm{M}$ counteracts the decrease in RUNX2 induced by BIL in bone tissue, SAOS2, MLO-A5 and MLO-Y4 cells.

Conclusions: The retained substances of cholestasis, particularly bilirubin, cause noxious effects on transcription factors of osteoblast differentiation and on osteoclastic activators in bone tissue and in osteoblastic and osteocytic cells. Ursodeoxycholic acid reverses the harmful effects of bilirubin. These results provide new insights into the low bone formation and at some stages, high resorption, associated with chronic cholestasis

Disclosure of Interest: None declared

DOI: 10.1136/annrheumdis-2018-eular.3649

\section{SAT0069 ABNORMAL BONE AND CARTILAGE METABOLISM COULD BE ANTAGONISED BY PULSED ELECTROMAGNETIC FIELDS (PEMFS) AND TNF-A AND IL-6 GENE KNOCKOUTS IN A SIMILAR MECHANISM}

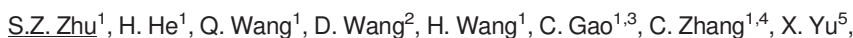
C. $\mathrm{He}^{1,3} \cdot{ }^{1}$ Rehabilitation Medicine, West China Hospital, Sichuan University; ${ }^{2}$ School of Aeronautics and Astronautics, Sichuan University; ${ }^{3}$ Institute for Disaster Management and Reconstruction, Sichuan University-The Hong Kong Polytechnic University, Chengdu; ${ }^{4}$ Rehabilitation Medicine, Southwest Medical University, Luzhou; ${ }^{5}$ Laboratory of Endocrinology and Metabolism, West China Hospital, Sichuan University, Chengdu, China

Background: Pulsed electromagnetic fields (PEMFs), as a safe and non-invasive method, could positively affect bone and cartilage metabolism. However, the effect and underlying mechanisms of PEMFs on osteoporosis and osteoarthritis remain poorly understood.

Objectives: The present study is designed to investigate the effect of PEMFs on osteoporotic bone and degenerative cartilage together with its potential molecular mechanisms in mice with different gene background.

Methods: Twenty 12 week male and Female wild-type (WT), TNF $\alpha$ knockout $\left(\mathrm{TNF}^{-/-}\right)$or IL6 knockout (IL6 ${ }^{-/}$) mice, respectively, were sham-operated (SHAM) or subjected to destabilisation of the medial meniscus (DMM) and ovariectomy (OVX) surgeries. After surgeries, WT mice were equally assigned to the non-treatment and PEMFs groups. Mice in PEMFs group were subjected to daily 1 hour PEMFs exposure with $8 \mathrm{~Hz}, 3.8 \mathrm{mT}$ (peak value). Then all mice were euthanized after 4 weeks. Bone mass and subchondral microarchitecture were determined using micro-CT. Bone and cartilage metabolism was assessed by histological analysis, serum analyses, qRT-PCR and Western-Blot.

Results: The surgical models of osteoporosis and osteoarthritis were proved successful evidenced by the analysis of micro-CT data and histological analysis. The bone loss and damaged cartilage were largely repaired by TNF $\alpha$ and IL6 gene knockout and partially inhibited by PEMFs exposure. Interestingly, no difference 